mimbre del bodegón, muy próximos a la Adoración de los Pastores (1675), del Museo de Zamora, hacen pensar que esta Anunciación se pintase en la década de los años setenta. Aún se puede reafirmar esta hipótesis, si se aprecia que el ángel de la Imposición de la Casulla a San Ildefonso (1679) guarda ciertas similitudes con el de este lienzo y que la disposición radial del halo divino de la Virgen o el tono «moderado» de la composición son las propias de estos años. Recuérdese por ejemplo que en la década anterior, mucho más «dinámica», pintó la Aparición de la Virgen a San Féliz de Cantalicio (1665) o su vaporosa Anunciación de 1667 a lo Francisco Rizi, con unos conceptos barrocos diferentes de tratamiento, escenografía y movimiento.

El lienzo por tanto ha de ser de la época y manera que parecía a Palomino ${ }^{18}$ «mejorada».

En cualquier caso, esta obra viene a ser un exponente más de su producción pictórica, imprescindible para conocer «la personalidad de este modesto artista, que sirvió los gustos devotos de su tiempo con cierta dignidad, y cuyo nivel de calidad no es inferior al de otros ${ }^{19}$.

Álvaro PIEDRA AdARVES

\title{
NUEVAS OBRAS DE MANUEL PEREIRA LOCALIZADAS EN TOLEDO (?)
}

Los últimos estudios de Jesús Urrea y Mercedes Agulló ${ }^{1}$ sobre el imaginero luso-madrileño Manuel Pereira han supuesto un decisivo paso para el conocimiento de su vida y su personalidad, pero ante este artista nos seguimos encontrando con el problema de su escasa obra conservada o localizada debido a las grandes pérdidas sufridas por nuestra escultura religiosa y a la falta de interés de investigadores por su estudio. De siempre, quienes se han adentrado por su labor, comentan la posibilidad de que su catálogo pueda ser aumentado estudiando las obras anónimas dispersas por las provincias limítrofes a la capital del Reino ${ }^{2}$. Ello nos ha llevado a tener los ojos atentos ante obras de calidad del siglo XVII que pudieran hallarse en la ciudad de Toledo o en lugares de su entorno. La bibliografía tradicional toledana de siempre dio como obras de Pereira las esculturas de la fachada de la antigua iglesia de la Trinidad, hoy desaparecidas y sólo conocidas por malas fotografías ${ }^{3}$ y la Inmaculada y los escudos del Cardenal Aragón que presiden la fachada del Monasterio de Madres Capuchinas, obra muy hermosa pero de no fácil adjudicación a Pereira como ya venimos apuntando en varias ocasiones y sobre las que en breve volveremos a insistir detenidamente ${ }^{4}$.

Aunque conocidas desde hace tiempo, y una de ellas con antigua atribución a Alonso Cano, ha sido últimamente cuando hemos reparado en dos esculturas parejas que representan al

\footnotetext{
18 Haciendo uso de las declaraciones que realizó el biógrafo en 1694 (véase nota núm. 5), el estilo de nuestro pintor hubo de mejorar sensiblemente hacia los primeros años de los sesenta, lo que coincide en parte con el inicio de su plena madurez profesional.

19 Pérez Sánchez, A. E., Art. cit., 1966, pág. 313.

1 Urrea, Jesús, «Introducción a la escultura barroca madrileña. Manuel Pereira», BSAA, t. XLIII, 1977, págs. 253-268. Agulló y Cobo, Mercedes, «Manuel Pereira, Aportación documental», BSAA, t. XLIV, págs. 257-278.

${ }^{2}$ Gómez-Moreno, M. ${ }^{a}$ Elena, Escultura del siglo XVII, t. XVI de Ars Hispaniae, Madrid, 1963, págs. 109-118. Urrea, Jesús, o.c.

3 Una fotografía de esta fachada con las antiguas esculturas aparece en la obra de Julio Porres, Historia de las calles de Toledo, Ed. Zocodover, Toledo, 1982, t. III, pág. 1473.

${ }^{4}$ Nicolau Castro, Juan, «La Inmaculada en el arte español y toledano», Toletum, t. 31, 1984, págs. 85-118. Idem, «Las esculturas italianas del Transparente de la Catedral de Toledo», Archivo Español de Arte, n. ${ }^{\circ} 273$, 1996, págs. 97-106.
} 


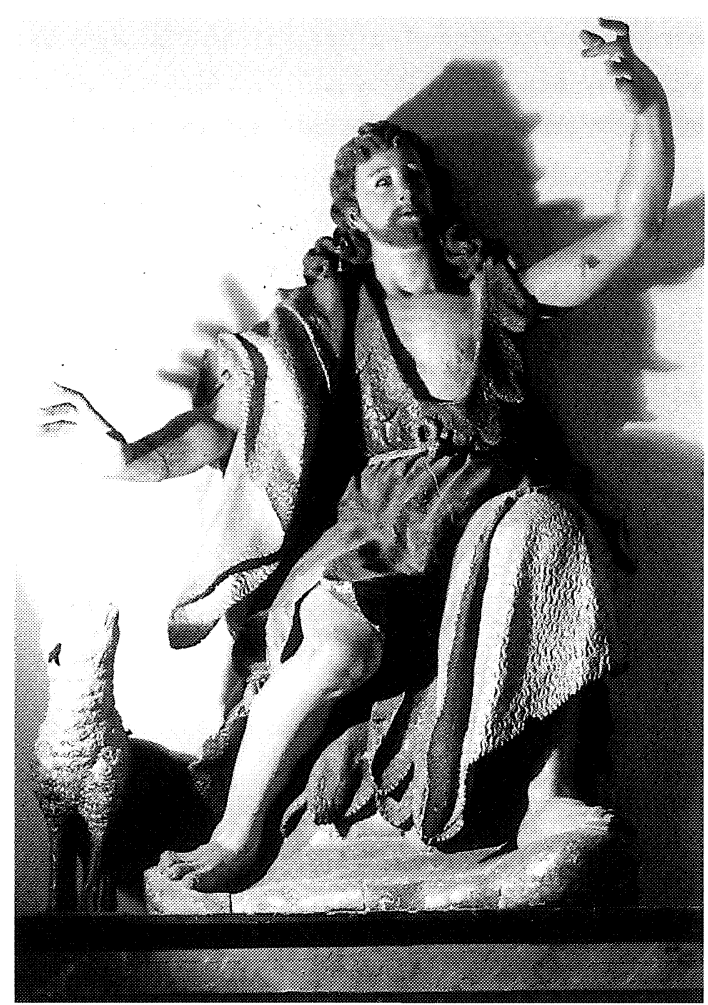

18

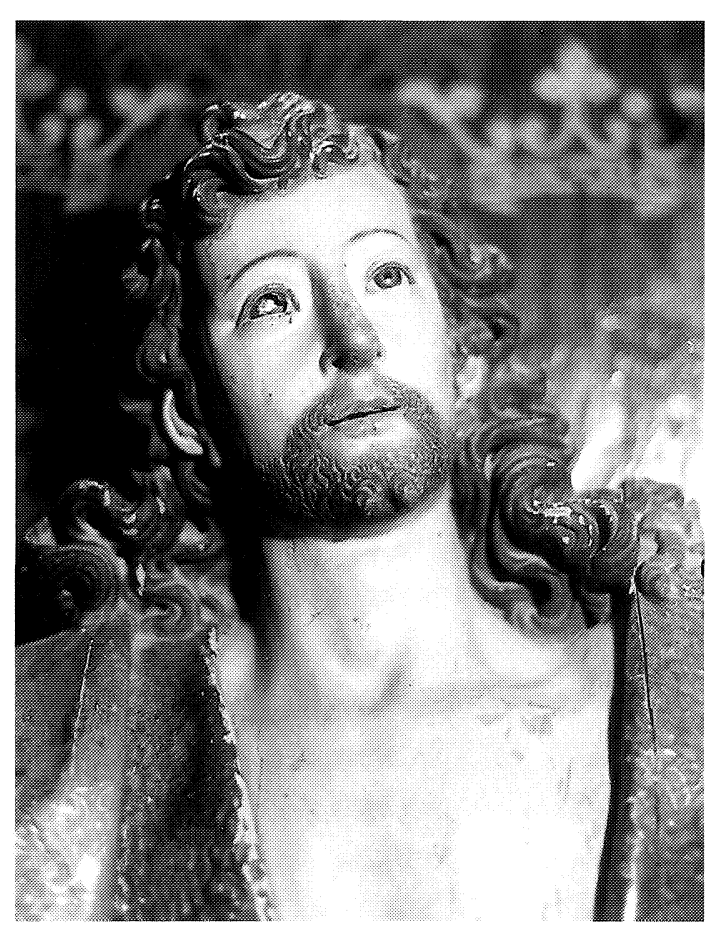

19

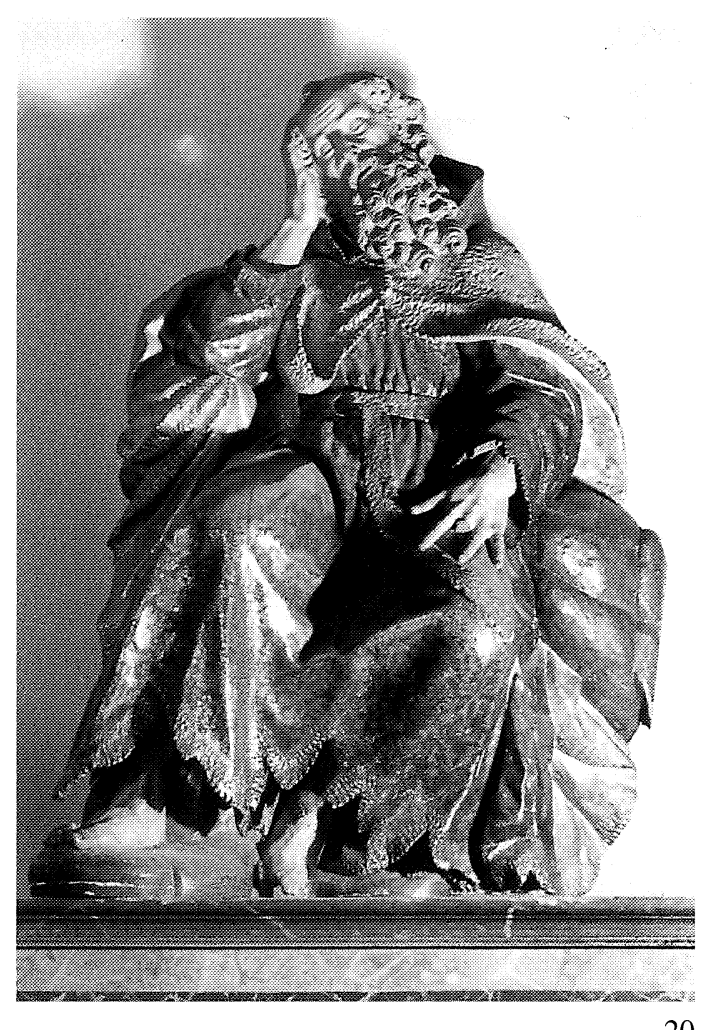

20

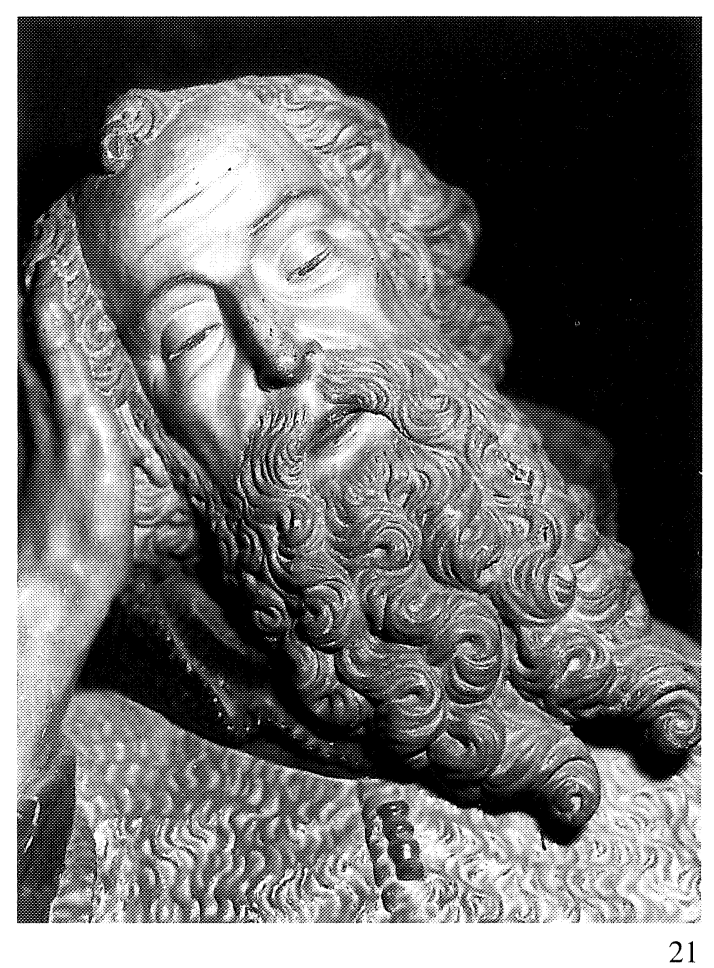

Figs. 18-21. ¿Manuel Pereira?, San Juan Bautista, conjunto y detalle; y El profeta Elías, conjunto y detalle. Toledo, Iglesia de Santo Tomé. 
profeta Elías y a San Juan Bautista (Figs. 18-21) y que se encuentran bajo dos arcos laterales, en el muro del presbiterio, de la iglesia toledana de Santo Tomé sobre laudas sepulcrales de los Condes de Fuensalida. La que llamó primeramente nuestra atención fue el San Juan Bautista, de manera especial cuando la pusimos en relación con el documento que Mercedes Agulló publicó del encargo de una escultura de este Santo para Toledo que hacía al escultor Manuel Pereira el vecino de la ciudad D. Antonio de Berástegui, el 12 de junio de 1661, amoldándose a un dibujo que remitía el propio escultor ${ }^{5}$. Según este documento, Pereira se comprometía a realizar, por el precio de 2.000 rs., «una hechura del señor San Juan Bautista de siete pies de alto sobre un peñasco que ha de tener el altor conveniente, en conformidad del dicho dibujo, con sus ynsignias de cordero y Cruz, y el Santo a de ser güeco para que no pese y encananiado (encamonado) por de dentro para más fortificación, y la piel a de ser pintada y realçada con oro molido lo que conviniera para su hermosura, y la capa o manto del Santo a de ser colorada hecho un chamelote ${ }^{6}$ de oro molido, y el calor del rostro y demás desnudo del Santo, moreno, tam graçioso como viere que conviene el dicho M. Pereira para salir mejor y todo a de ser bien acabado por todas partes». Sigue a continuación una prolija descripción de cómo debería ser una gran peana que desgraciadamente no parece se haya conservado. La figura de la parroquia de Santo Tomé coincide en todo con lo que se señala en este documento salvo en las medidas que parecen menores, lo cual no es óbice para mantener la atribución ya que este cambio no era infrecuente al tener en ocasiones que rectificarse las de un primer contrato. La actual mide aproximadamente 1,35 ms., sin tener en cuenta la gran peana que no nos ha llegado.

El Santo aparece sentado sobre una roca en gran parte dorada, muestra las piernas separadas echando hacia atrás la derecha en un movimiento elegante y rebuscado. Los brazos los abre declamatoriamente dibujando una diagonal al alzar el izquierdo y bajar el derecho. Las manos finamente talladas tienen dedos muy separados de dibujo expresivo, la izquierda, alzada, muestra el gesto de coger un estandarte que sería la tradicional cruz con el Agnus Dei de que habla el contrato. Muy hermosa es la cabeza de mirada elevada y perdida, enmarcada en abundante y rizada cabellera que cae copiosamente por la espalda. Las facciones del rostro siguen muy de cerca las de otras figuras de Pereira, «el rostro implorante, la mirada dirigida a lo alto, las cejas marcadamente arqueadas, la barba fina y el cabello abundante y trenzado, el rostro y nariz afilada, la boca entreabierta, las manos elegantes y expresivas». Estas palabras con las que describe Urrea el Ecce-Homo de las Carmelitas de Larrea en Vizcaya, con la salvedad del menor dramatismo del San Juan, podrían ser perfectamente válidas para esta escultura ${ }^{7}$. El Santo viste túnica de piel ceñida a la cintura con una cuerda que se anuda de modo semejante a las lazadas que Pereira realiza en muchas de sus Vírgenes. Por el reverso muestra la lana del animal mientras el anverso muestra el cuero soberbiamente policromado según la técnica del estofado formando hermosos dibujos que recuerdan el manto de la Virgen del Rosario de Santo Domingo de Bemfica en Lisboa. Sobre el hombro derecho sostiene amplio manto de piel blanca que rodea la espalda y aparece de manera elegante sobre la rodilla izquierda. La talla minuciosa de esta piel aparece realzada «con oro molido» como indica la documentación en el anverso, mientras que en el reverso sobre la blancura de la pieza se insinúan los dibujos del estofado de la túnica. A sus pies aparece el cordero felizmente conservado aunque se advierte haber sido tallado para incrustarlo en una peana, toques de oro realzan también su piel. Como expresa la documentación el Santo aparece hueco y «encamonado» y no conserva la parte de la espalda, si es que alguna vez la tuvo, pues más bien parece que la figura pudo realizarse para ser colocada sobre un respaldo o retablo fijo lo que impediría su talla posterior.

\footnotetext{
${ }^{5}$ Agulló y Cobo, Mercedes, o.c., pág. 275.

${ }^{6}$ Chamelote o camelote es, según el Diccionario de la Real Academia de la Lengua, un tejido fuerte e impermeable hecho con piel de camello o cabra mezclado con lana.

${ }^{7}$ Urrea, Jesús, o.c., pág. 262.
} 
Su actual estado de conservación no es bueno, se ha roto y desprendido parte de la piel flotante de la túnica descubriéndose el muslo derecho que iría cubierto. Tiene muy deteriorada en partes la policromía y el mayor daño se debe a haberse roto su ojo derecho. El cordero debe también su falta de gracia a tener cortado parte del morro.

Al lado del San Juan se conserva la imagen del profeta Elías ya conocida de antiguo con atribución gratuita a Alonso Cano que ya rebatía D. Manuel Gómez Moreno en $1926^{8}$ y que M. Martínez Chumillas lo fecha en el siglo XVI ${ }^{9}$. Representa a Elías durmiendo y sin duda formó pareja con el Santo Precursor, las mismas medidas, el mismo tratamiento de talla, la misma espléndida policromía con idénticos motivos, la misma manera de vestir con túnica marrón de piel vuelta y manto blanco realzado con toques de oro. El profeta también aparece sentado sobre una roca con las piernas en rebuscada postura y dejando solo libres los pies descalzos, espléndidos de dibujo y talla, bajo la túnica. El brazo derecho apoya sobre la roca y con él sostiene la cabeza dormida, el brazo y la mano izquierda caen abandonados sobre el muslo. En la escultura destaca el rostro del viejo profeta enmarcado por el borde de la capucha de piel oscura. Muestra facciones de viejo perfectamente logradas, amplísima frente surcada de arrugas, nariz larga como el San Juan pero de marcada forma aguileña, pómulos salientes y mejillas hundidas lo mismo que las cuencas de los ojos en cuyo fondo destacan los pesados párpados entornados dejando ver ligeramente el globo del ojo. La boca, como es habitual en Pereira, aparece ligeramente abierta como dejando escapar la respiración o un suspiro. Pero lo que infunde fuerte carácter a este rostro es la amplísima barba que lo enmarca, de larguísimos cabellos acaracolados hasta lo inverosímil, está trabajada siguiendo un dibujo minucioso y prolijo que nos hace recordar un material blando como el barro. Muy típico es el acaracolamiento en que terminan las dobles puntas de la barba que, también, aunque con un tratamiento distinto al ser un adolescente, aparece en el San Juan. Como éste, la estatua está trabajada hueca y la parte posterior sin tallar sigue apuntando a la procedencia de un retablo.

Debido a su abarrocada barba este San Elías se ha puesto también repetidas veces en relación con Juan A. Villabrille y Ron, pero la técnica es distinta. Las gubias se mueven en Villabrille de manera diferente, con surcos más profundos, rizos más hinchados y efectos de claroscuro más dramáticos y barrocos. La diferencia resulta aun más evidente que en la barba en el tratamiento de las cejas que Villabrille nunca reduce a una línea sino que las talla mechón a mechón ${ }^{10}$.

El recuerdo en estas esculturas de obras conocidas de Cano es indudable y ello no hace sino reforzar la vinculación con Pereira dados los contactos que ambos tuvieron y la influencia que Cano ejerce sobre su obra. El Dr. Urrea amablemente nos comunicaba su convicción de que obras de Pereira se han atribuido con curiosa insistencia al propio Alonso Cano.

Sobre el origen de ambas imágenes nada definitivo podemos aportar a pesar de nuestras indagaciones. Rafael Ramírez de Arellano en sus Parroquias de Toledo, al tratar sobre Santo Tomé nada en absoluto aporta incluso al incluir varios inventarios ${ }^{11}$. Las guías antiguas sobre Toledo al dar muy pocas referencias sobre escultura nada ayudan tampoco. Nada nos aporta Ponz ${ }^{12}$, ni Amador de los Ríos ${ }^{13}$, ni Ramón Parro ${ }^{14}$, ni el Vizconde de Palazuelos ${ }^{15}$, ni Gonzá-

\footnotetext{
${ }^{8}$ Gómez-Moreno, Manuel, «Alonso Cano, escultor», Archivo Español de Arte y Arqueología, n. ${ }^{6}$ 6, 1926, págs. 177-214.

${ }^{9}$ Martínez Chumillas, Manuel, Alonso Cano, Madrid, 1949, págs. 273 y 305.

${ }^{10}$ Marcos Vallaure, Emilio, «Juan Alonso Villabrille y Ron, escultor asturiano», BSAA, t. XXXVI, 1978, págs. 147-

"Ramírez de Arellano, Rafael, Las parroquias de Toledo, Toledo, 1921, págs. 271-281.

12 Ponz, Antonio, Viage de España, Madrid, 1787, t. I.

13 Amador de los Ríos, José, Toledo Pintoresca, Ed. El Albir, S. A., Barcelona. 1976.

${ }_{14}$ Perro, Sixto Ramón, Toledo en la mano, I.P.I.E.T., Diputación Provincial, Toledo, 1978.

15 Palazuelos, Vizconde de, Toledo. Guía artística práctica, Toledo, 1890.
} 158. 
lez Simancas ${ }^{16}$, ni Ainaud de Lasarte a pesar de incluir una fotografía del San Elías ${ }^{17}$. Últimamente nuestras pesquisas van encaminadas al antiguo Monasterio de Carmelitas Calzados ya desaparecido ${ }^{18}$ o a San Juan de los Reyes. En un artículo publicado en 1928 por F. J. Sánchez Cantón sobre el dibujo de Juan Guas conservado en El Prado ${ }^{19}$ encontramos una fotografía del interior de la iglesia de San Juan de los Reyes donde son claramente perceptibles las esculturas de San Juan Bautista y San Elías a uno y otro lado del retablo mayor, lo que nos lleva a pensar que o bien pudieron ser de allí o allí se recogieron como nos informa Parro se hizo con pertenencias de antiguas iglesias desaparecidas. En cualquier caso lo que está claro es que son piezas que han rodado por diversas iglesias toledanas.

Al margen de esta pareja de esculturas de clara vinculación con el escultor madrileño, queremos referirnos a otro conjunto de imágenes existente en Toledo realizado en Madrid por los mismos años y que presetan analogías suficientes con el mundo de Pereira como para que sean tenidas en cuenta. Las obras se encuentran en el Monasterio de Monjas Benedictinas, las vulgarmente llamadas Benitas, cuya iglesia se levanta entre 1633 y $1659^{20}$. Según documentó ampliamente Mercedes Agulló ${ }^{21}$ su hermoso retablo, absolutamente madrileño por diseño y ornamentación, es obra del ensamblador de la Corte, Alonso García, que lo realiza entre 1664 y 1665. El retablo alberga las imágenes de la Inmaculada (Figs. 22-23), titular del templo, y a los lados las figuras de San Pedro y San Benito (Figs. 24-25). En el medio punto de remate aparece la Trinidad. Todo el conjunto resulta uno de los más interesantes del Toledo barroco, del que queda por lamentar la pérdida del templete o custodia que realizaba el mismo ensamblador según especifica en el contrato y que tanto se echa a faltar. Muchos son los indicios que podrían apuntar a Pereira y que en espera de algún feliz hallazgo documntal aquí sólo queremos dejar planteado. La Inmaculada sigue el esquema que el escultor repite, dragón y peana de serafines sobre los que se alza la imagen ${ }^{22}$. Los serafines de la peana son de todos los elementos lo que más apunta al escultor pues los vemos casi idénticos en obras seguras suyas, sobre todo los del pedestal de la Virgen del Rosario de Santo Domingo de Benfica. Como apunta el Dr. Urrea al tratar esta imagen, los serafines son deliciosos pero no alegres ni juguetones, un halo de nostalgia les envuelve. De las Inmaculadas documentadas de Pereira la única segura conservada es la de las Agustinas Recoletas de Pamplona de $1649^{23}$ y aunque en principio parecen obras distintas tienen más de un elemento en común, la mirada dirigida hacia lo alto, la postura de brazos y manos y la caída del manto que ya se insinúa volando hacia el lado izquierdo en la de Pamplon y que con parecidos pliegues aunque con movimiento más amplio y abarrocado aparece en Toledo. Las facciones del rostro son también cercanas a Pereira, boca pequeña y entreabierta, nariz larga y cejas muy arqueadas, añadamos a todo ello esa concentración interior que se manifiesta en una expresión de nostalgia o ensueño.

${ }^{16}$ González Simancas, M., Toledo. Sus monumentos y el arte ornamental,Madrid, 1929.

17 Ainaud de la Sarte, J., Toledo, Guías artísticas de España, Ed. Aries, Barcelona.

${ }^{18}$ Mi gran amigo el padre carmelita Rafael Rey, gran especialista en iconografía carmelitana, me apunta sus sospechas sobre la posible procedencia de estas esculturas del desaparecido Monasterio del Carmen Calzado.

${ }^{19}$ Sánchez Cantón, F. J., «El dibujo de Juan Guas», Arquitectura, n. ${ }^{\circ} 115,1928$, págs. 1-11.

${ }^{20}$ Suárez Quevedo, Diego, Arquitectura barroca en Toledo. Siglo XVII, Caja de Ahorros de Toledo, Toledo, 1990, págs. 153-169. Martínez Caviró, Balbina, Conventos de Toledo, Ediciones El Viso, Madrid, 1990, págs. 314-339.

${ }^{21}$ Agulló y Cobo, Mercedes, «Tres arquitectos de retablos del siglo xvir: Sebastián de Benavente, José de la Torre y Alonso García»,Archivo Español de Arte, n. ${ }^{\circ} 184,1973$, págs. 391-399. Idem, Documentos sobre escultores, entalladores y ensambladores de los siglos XVI al XVIII, publicaciones del Departamento de H. ${ }^{a}$ del Arte, Valladolid, 1978, pág. 25.

${ }^{22}$ Así se especifica en el contrato que Pereira hace de una Inmaculada para la villa toledana de Sonseca. Imagen no existente en nuestros días y sobre la que ninguna noticia he podido hallar hasta la fecha. Ver Mercedes Agulló, «Manuel Pereira: Aportación documental», pág. 27.

${ }^{23}$ Segovia Villar, M. a del Carmen, «El convento de Agustinas Recoletas de Pamplona», BSAA, t. XLVI, 1980, págs. 255284. García Gainza, M. ${ }^{a}$ Concepción, Salve. 700 años de arte y devoción mariana en Navarra, Pamplona, 1994, pág. 109. 

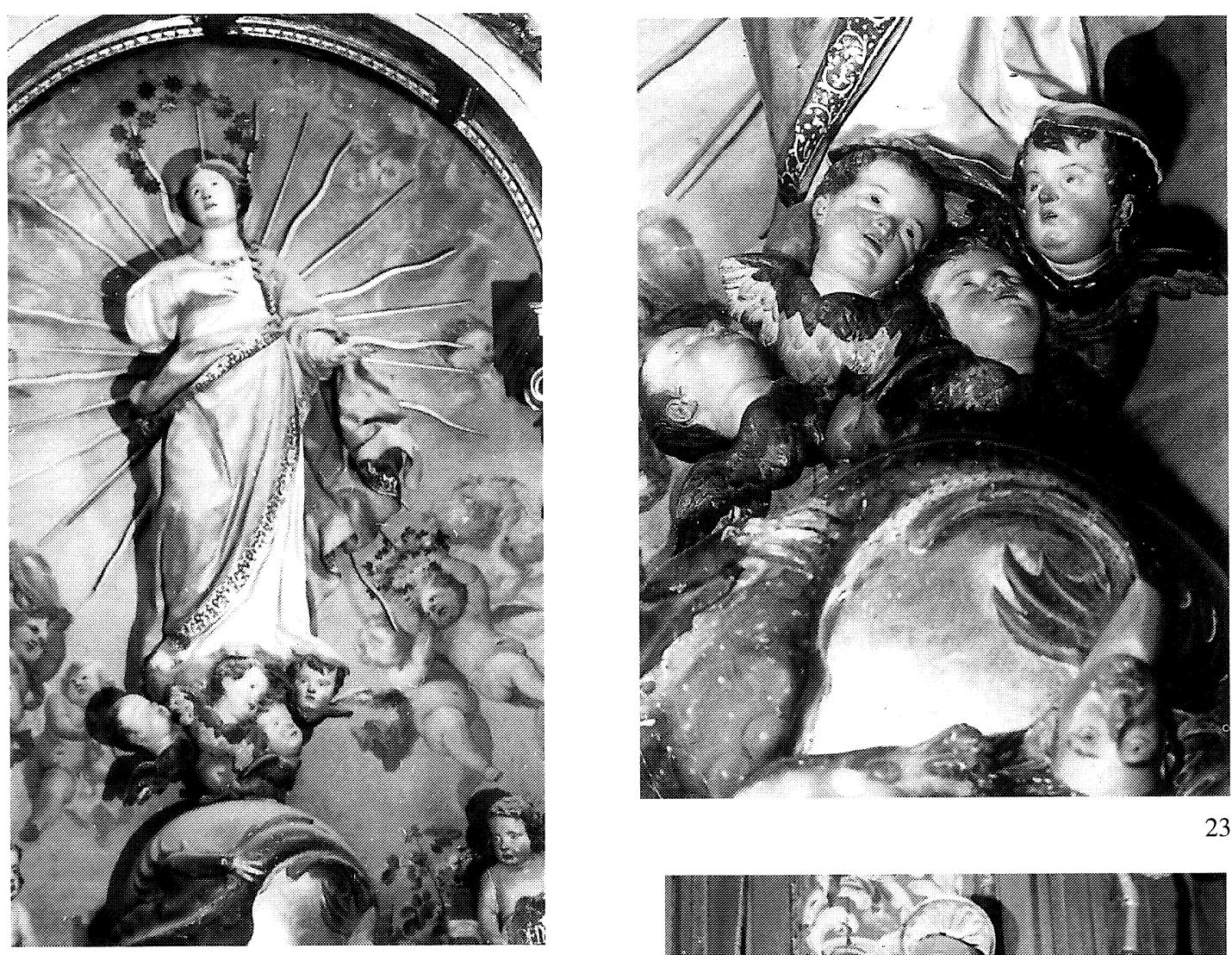

22
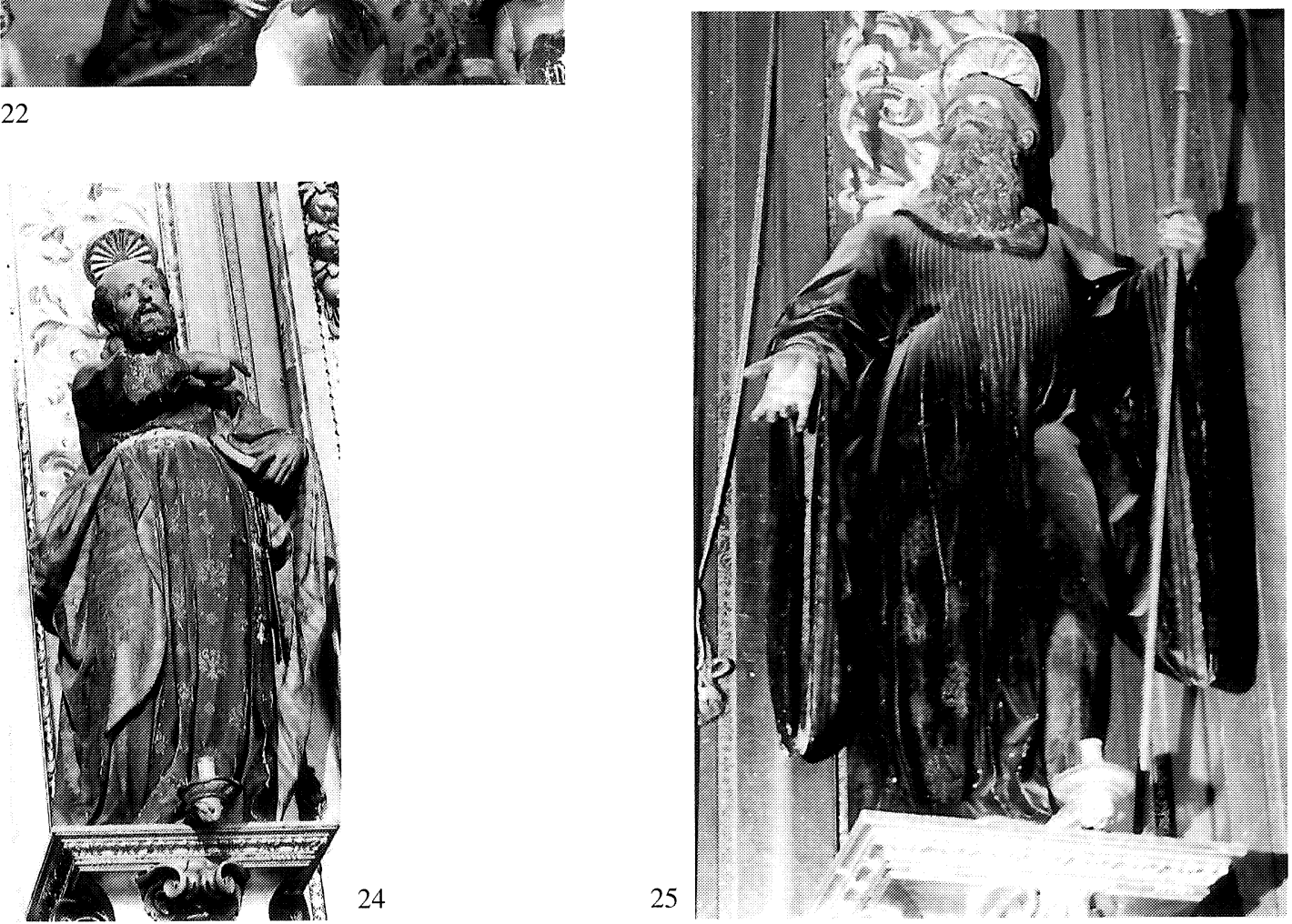

Figs. 22-23. ¿Manuel Pereira?, Inmaculada, conjunto y detalle.

Figs. 24-25. Escuela madrileña, San Pedro y San Benito. Toledo, Convento de Madres Benitas. 
Las figuras laterales de San Pedro y San Benito también recuerdan el mundo del esculto por su sobriedad y su firme apostura, además hay detalles que vemos en obras del autor madrileño, la barba del San Pedro recuerda en su tratamiento la manera blanda y sinuosa de la talla del profeta Elías, su rebuscada manera de llevar el libro recuerda al San Antonio de la fachada del Hospital de los Portugueses en Madrid y la policromía de sus ropas, aquí con colores planos, adornada con rameados dorados aparece en el San Marcos de Martín Muñoz de las Posadas. El San Benito resulta, sin embargo, más movido que los Santos frailes del Monasterio de San Plácido, en un tratamiento más barroco de su figura y curiosamente la barba se trabaja de modo muy distinto a la del San Elías que aquí describimos, a mechones largos y sueltos.

Aunque de modo indirecto, otras dos circunstancias apuntan al mundo madrileño en el que se desenvuelve Pereira. El pintor Francisco Camilo que policroma varias obras del escultor y con quien tuvo además relación de amistad también trabaja para este templo. Para él contrató una serie de lienzos de los que sólo se conservan los dos que presiden los retablos laterales cercanos al presbiterio ${ }^{24}$. Y por último, la fachada de la iglesia está presidida por una imagen de la Inmaculada, realizada en piedra de Tamajón, de formas macizas y carente en absoluto de gracia, que documentalmente sabemos realiza el escultor Manuel Correa ${ }^{25}$ quien colabora con Pereira y en ocasiones se hace cargo de alguna obra contratada por el maestro que éste se ve obligado a traspasar ${ }^{26}$.

JuAN Nicolau CASTRO Doctor en Historia del Arte

\section{LAS COLGADURAS DE SEDA DEL SALÓN DE MARÍA LUISA EN LA CASA DEL LABRADOR}

Si una de las estancias más bellas y espectaculares de la Casa del Labrador de Aranjuez es, sin duda, la del «Salón de María Luisa», se debe en gran medida a las colgaduras con que se hallan vestidas sus paredes, se adornan sus ventanas ys puertas y se tapizan sus muebles (Figs. 26-27).

Ya desde antiguo, se reconoce el mérito de estos tejidos y así se reseña en la Historia descriptiva del Real Sitio de Aranjuez, escrita por Cándido López y Malta quien al hablar de este salón, no duda en calificarlo de «sobresaliente», especificando que «sus paredes están todas forradas de sedería esquisita, bordada toda de vistas de italia y paisajes de composición, de un mérito tal que no acertaría a describirlo la mejor cortada pluma» ${ }^{\text {. }}$

Tan excepcional colgadura fue realizada en la mejor y más prestigiosa manufactura sedera de la Europa de finales del siglo XVIII, la de Camille Pernon, que ya había intervenido en la decoración de diferentes estancias en El Pardo, El Escorial y Madrid y a quien se deben las mejores sederías de este palacete de recreo ${ }^{2}$.

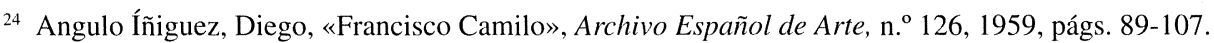

${ }^{25}$ Suárez Quevedo, Diego, o.c., pág. 165.

${ }^{26}$ Esto ocurre, por ejemplo, con la escultura del retablo de la iglesia de Torrejón de Velasco, contratado por Pereira y traspasado a Manuel Correa. Ver Mercedes Agulló, «Manuel Pereira: Aportación documental», pág. 276.

' C. López y Malta, Historia descriptiva del Real Sitio de Aranjuez, Aranjuez, 1868, págs. 312 - 313.

2 Está próximo a publicarse el estudio que a lo largo de varios años he venido elaborando sobre todos y cada uno de los textiles que la fábrica de Pernon hizo para la Casa del Labrador. En él se ofrecerá también información sobre los autores de las vistas que sirvieron de modelo para los bordados que decoran las paredes de esta estancia y del salón de billar.
} 